\title{
Seasonal variations in dissolved nitrous oxide concentrations in a eutrophic shallow lake without anaerobic layer
}

\author{
Shinya Hashimoto ${ }^{1}$, Hua Yan Sun ${ }^{2}$, TAKeshi Nakamura ${ }^{1}$, \\ YUKIHIRO NOJIRI ${ }^{3}$ and AKIRA OTSUKI ${ }^{1}$ \\ Department of Marine Science \& Technology, Tokyo University of Fisheries, \\ 4-5-7 Minato-ku, Tokyo 108, ${ }^{1}$ \\ Kenkomayonaise Co., Ltd., Suginami-ku, Tokyo $168^{2}$ and \\ National Institute for Environmental Studies, 16-2 Onogawa, Tsukuba, Ibaraki 30533, Japan
}

(Received September 7, 1992; Accepted April 30, 1993)

\begin{abstract}
Seasonal variations in dissolved nitrous oxide concentrations in Lake Kasumigaura were measured to examine a eutrophic shallow lake without anaerobic layer as one of natural nitrous oxide emission sources. Samples were monthly taken using a Go-Flo sampler at 6 sites including lake center during April, 1991 to March, 1992. Dissolved nitrous oxide in the lake water samples was measured by an automatic analyzer consisting of purge and trap system and GC-ECD detector.

The concentrations in surface water at lake center ranged from $9 \mathrm{nM}$ to $21 \mathrm{nM}$ and there was no large vertical difference. On the other hand, those at the inner-most part of Takahamairi Bay, where heavy blooming of cyanobacteria occurs every summer, ranged from $13 \mathrm{nM}$ in summer to $63 \mathrm{nM}$ in autumn. The variation pattern that nitrous oxide concentrations in Takahamairi Bay were high in autumn to winter and low in summer was similar to that of nitrate-nitrogen concentration.

The present results show that nitrous oxide concentrations in surface lake waters at all sites in this lake were supersaturated or at least equilibrated, and suggest that nitrous oxide may be being produced in many eutrophic shallow lakes, even though anaerobic layer is not formed in summer, and that they can be one of the natural nitrous oxide emission sources.
\end{abstract}

\section{INTRODUCTION}

Although nitrous oxide concentration in the atmosphere is known to be increasing by about $0.2 \%$ per year (e.g., Weiss, 1981), a significant portion of the emission sources remains to be identified (Benarde, 1992). Because of its importance on global climatic processes, identification of all significant sources is particularly important (Thiemens \& Trogler, 1991; Rosswall, 1991; Benarde, 1992).

There exist two mechanisms for the biogenic production of nitrous oxide in aquatic environment. One is reductive microbial production in which it is produced during denitrification process (Knowles et al., 1981; Yoh et al., 1983; Terai et al., 1987), and the other is oxidative microbial production in which it is produced during nitrification process (Yoh et al., 1988). In most aquatic environment, nitrification would exceed denitrification because anaerobic conditions are not common on the earth. However, phytoplankton in euphotic zone of many lakes and reservoirs rapidly consumes ammonium ion before nitrification occurs (Wetzel, 1975). Therefore, the concentrations of ammonium ion in surface waters of many lakes and reservoirs, which are not influenced by human activity, are extremely low or undetectable and consequently the production of nitrous oxide in surface waters by nitrification would be limited due to the absence of ammonium ion.

Many studies have been undertaken on reductive microbial processes in eutrophic lakes with anaerobic hypolimnion and estuaries to evaluate the role of denitrification in nitrogen cycle, and the importance of dissolved oxygen-depleted hypolimnion and sediment surface has been 
made clear (e.g., Knowles, 1982; Seitzinger, 1988). However, eutrophic shallow lakes without anaerobic layer have not been examined as one of natural nitrous oxide emission sources, because denitrification process has been considered to be the most important mechanism of nitrous oxide production (Benarde, 1992).

Many eutrophic lakes in the world are shallow and receiving huge amounts of nitrogenous nutrients by inflows from polluted rivers, effluents from wastewater treatment plants, and precipiation, which have caused eutrophication of the lakes. However, it seems that there is little report on the accumulation of nitrogenous compounds in these lakes, except for sediment surface layer (e.g., Otsuki et al., 1993). This suggests that a considerable portion of loaded total nitrogen to such lakes must be being removed into the atmosphere as nitrogen gas during denitrification processes as one of natural purification mechanisms, and consequently nitrous oxide as an intermediate would be produced (Koike et al., 1984; Seitzinger, 1988) and be emitted to the atmosphere.

In the present study, we examined seasonal variation in dissolved nitrous oxide concentration in eutrophic shallow Lake Kasumigaura in order to evaluate eutrophic shallow lakes without anaerobic layer as one of the natural nitrous oxide emission sources.

\section{Materials and methods}

Table 1 shows general hydrological data of Lake Kasumigaura. Lake Kasumigaura, the second largest lake in Japan, is located about $70 \mathrm{~km}$ northeast of Tokyo. This lake is hypertrophic and is known as a most productive lake in Japan. This has two large bays, which are called Takahamairi and Tsuchiurairi. The lake basin is smooth and shallow. Due to its shallowness and strong vertical mixing of the lake water by wind, distinct thermal stratification does not develop even in summer period except for a few calm days. Thus, anaerobic conditions are rarely observed. Water temperature at the lake center is the lowest at $2-5^{\circ} \mathrm{C}$ in February and the highest at $26-30^{\circ} \mathrm{C}$ in August. The lake is receiving
Table 1. General hydrological data of Lake Kasumigaura

\begin{tabular}{|c|c|}
\hline \multicolumn{2}{|l|}{ Lake surface area $\quad 171 \mathrm{~km}^{2}$} \\
\hline \multicolumn{2}{|c|}{$\begin{array}{l}\text { Lake surface area } 171 \mathrm{~km}^{2} \\
\text { Mean depth } 4 \mathrm{~m}\end{array}$} \\
\hline \multicolumn{2}{|c|}{ Maximum depth $\quad 7.4 \mathrm{~m}$} \\
\hline \multicolumn{2}{|c|}{ Lake volume $\quad 800$ million $\mathrm{m}^{3}$} \\
\hline \multicolumn{2}{|l|}{ Inflow water volume } \\
\hline Annual rainfall & \\
\hline \multicolumn{2}{|l|}{ Mean lake surface level } \\
\hline \multicolumn{2}{|l|}{ Highest water temperature } \\
\hline \multicolumn{2}{|l|}{ Lowest water temperature } \\
\hline \multicolumn{2}{|l|}{ Annual nitrogen loading } \\
\hline \multicolumn{2}{|c|}{ Annual phosphorus loading $\quad 400-600$ tons (1) } \\
\hline
\end{tabular}

(1) Ibaraki University (1977), Goda et al. (1984), Ebise (1990)

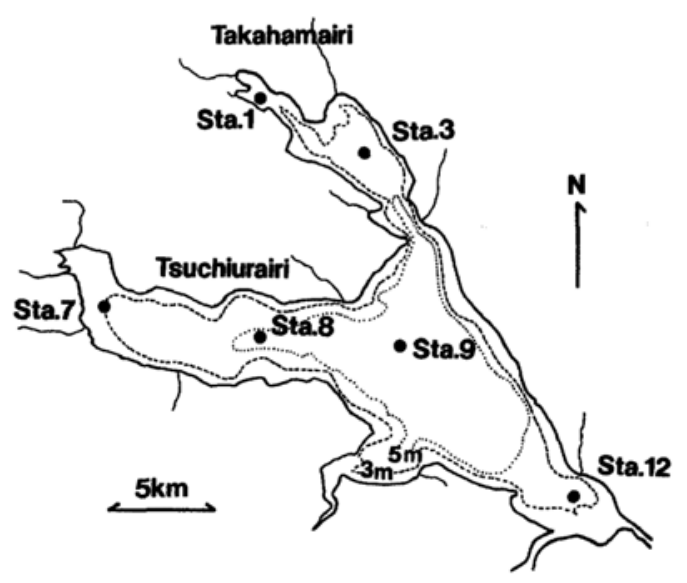

Fig. 1. Sampling stations in Lake Kasumigaura.

about $3,000-4,500$ tons $\mathrm{N}$ and $400-600$ tons $\mathrm{P}$ from several sources (Ibaraki University, 1977; Goda et al., 1984) and total nitrogen loading was reported to be increasing (Ebise, 1990).

Figure 1 shows study sites. Samples were monthly taken using a Go-Flo sampler at 6 sites including lake center during April, 1991 to March, 1992. A $100 \mathrm{ml}$ glass bottle was used for sample preservation. After overflow of more than $200 \mathrm{ml}$ of sample water, $0.5 \mathrm{ml}$ of mercuric (II) chloride was added and the sample bottle was immediately capped with a hand-clipper. The concentration of mercuric (II) chloride in the sample bottle was about $140 \mathrm{mg} \mathrm{l}^{-1}$.

Figure 2 shows a schematic flow chart of nitrous oxide analysis. Dissolved nitrous oxide in lake water samples was measured with an automatic analyzer consisting of sample injector 


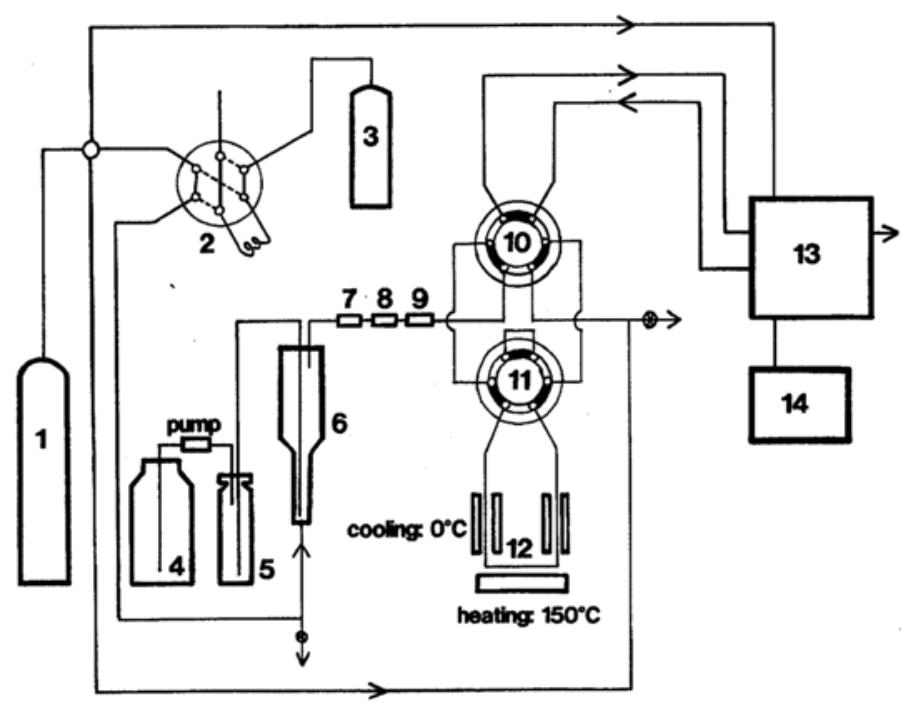

Fig. 2. Schematic diagram of $\mathrm{N}_{2} \mathrm{O}$ analysis system. $1, \mathrm{~N}_{2}$ cylinder; 2, Standard gas sampling system; 3, $\mathrm{N}_{2} \mathrm{O}$ standard gas cylinder; 4, Hexane bottle; 5, Sample bottle; 6, Purging chamber; 7, Silica gel; 8, Molecular sieve $3 A ; 9$, Ascalite; 10, 11, six-way valve; 12, heater and cooler with molecular sieve $13 X ; 13$, Gas chromatograph with ECD; 14, Integrator.

system, purging chamber, adsorption and desorption column with cooling and heating system, gas chromatograph with ECD detector, and calibration system. This automatic analyzer was newly developed by us and DKK cooperation. After the sample bottle is set, sample water is pushed out by pumping hexane from its reservoir into the purging chamber, and then purged by nitrogen gas. After trapping nitrous oxide onto this cooled Molecular Sieve 13X column, it is released by heating and determined with the ECD detector. An integrator controls this whole system according to time-schedule.

The analytical conditions for determination of nitrous oxide were shown in Table 2. The following analytical parameters were optimized: sample volume, purge gas, flow rate, the length of purging (trapping) time, cooling and heating temperature of the trap, gas chromatograph column, oven temperature, carrier gas flow rate and ECD detector temperature. The detection limit of this system was about $2 \mathrm{nM}$ using $14.2 \mathrm{ml}$ water sample. The reproducibility obtained from six times measurements using $14.2 \mathrm{ml}$ of nitrous oxide solution containing $9.8 \mathrm{nM}$ was better than $\pm 3.0 \%$. The analysis time of one sample
Table 2. Analytical conditions for determination of nitrous oxide by GC-ECD

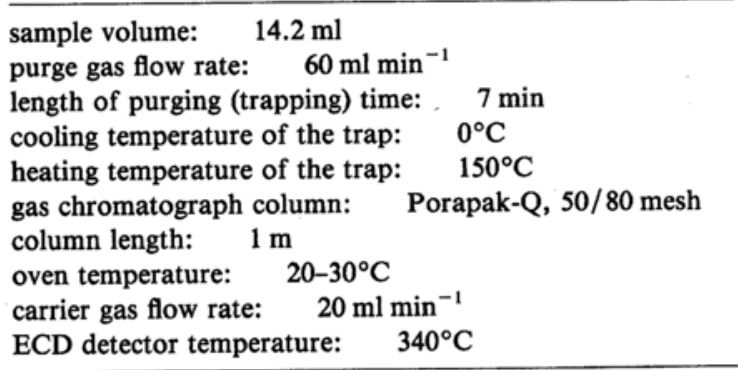

was within $30 \mathrm{~min}$.

\section{Results AND Discussion}

Figure 3 shows seasonal variation in dissolved nitrous oxide concentrations at Stations 3 and 9 as representative examples. The observed concentrations in surface lake water in the main basin including lake center (Stations-7, 8, 9, and 12) ranged from $9 \mathrm{nM}$ in summer to $25 \mathrm{nM}$ in winter, and vertical distribution of dissolved nitrous oxide was nearly uniform as were those of major cations $\left(\mathrm{Na}^{+}, \mathrm{K}^{+}, \mathrm{Mg}^{2+}, \mathrm{Ca}^{2+}\right)$ and anions $\left(\mathrm{Cl}^{-}, \mathrm{SO}_{4}^{2-}\right)$ (Kawai et al., 1984). Large 

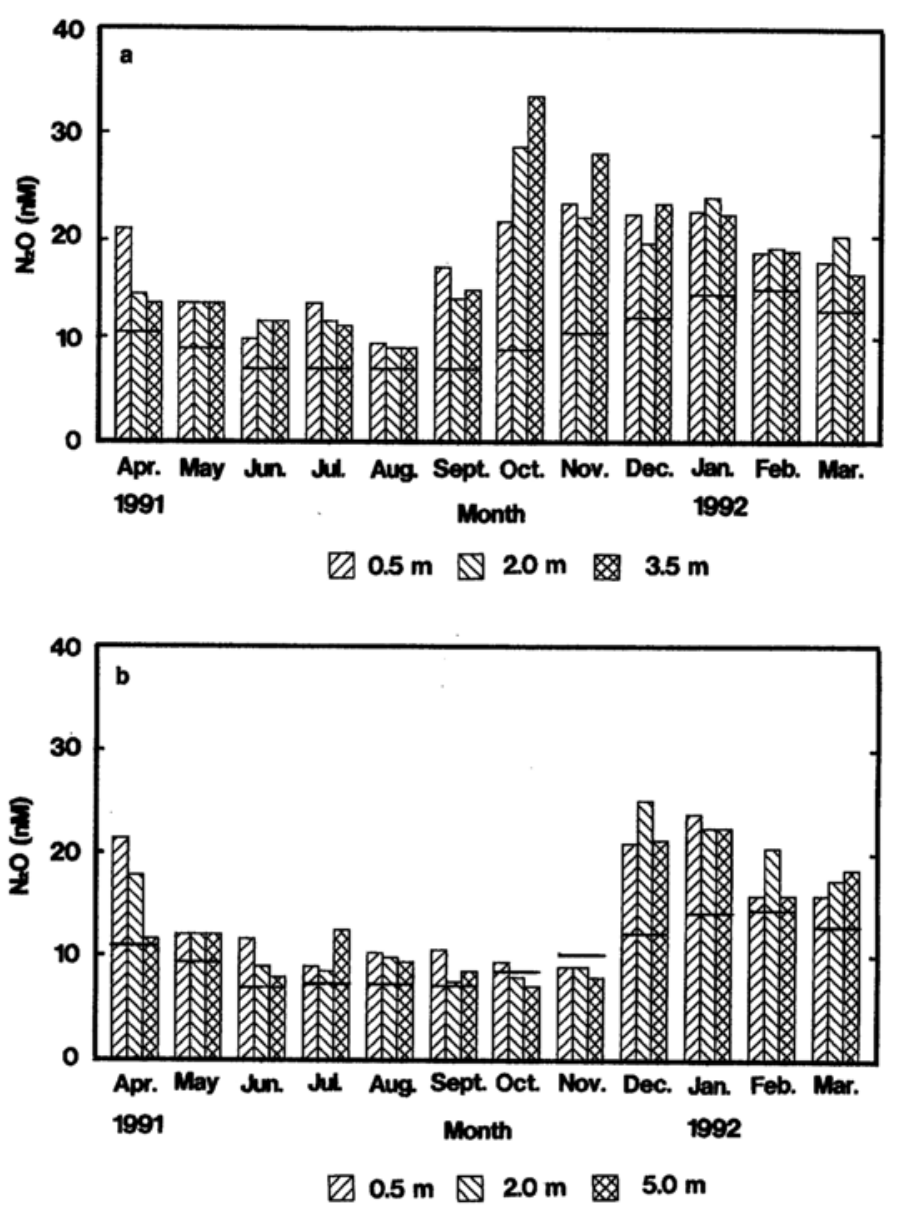

Fig. 3. Seasonal variations in dissolved nitrous oxide concentrations at Stations-3 and 9. Horizontal lines indicate the solubility of atmospheric nitrous oxide estimated from lake water temperature. a: Station-3, sampling depth; 0.5, 2.0, 3.5 m. b: Station-9, sampling depth; 0.5, 2.0, $5.0 \mathrm{~m}$.

seasonal variations were observed between summer and winter in the main basin. On the other hand, in Takahamairi Bay where the heavy bloom of cyanobacteria occurs every summer, the concentrations ranged from $13 \mathrm{nM}$ in summer to $63 \mathrm{nM}$ in autumn and large seasonal variations were observed between summer and autumn. However, the abundances of dissolved nitrous oxide at Station-1 $\left(26 \mathrm{uM} \mathrm{m}^{-2}\right.$ in minimun and $126 \mathrm{uM} \mathrm{m}^{-2}$ in maximum) was considerably smaller than those at lake center (54 $\mathrm{uM} \mathrm{m}^{-2}$ in minimum and $150 \mathrm{uM} \mathrm{m}^{-2}$ in maximum). This would imply that significant portions of nitrous oxide produced were shortly released into the atmosphere at the shallower bay.
On the assumption that the equations of nitrous oxide solubility by Weiss and Price (1980) are applicable to this lake water system, we estimated the solubilities of atmospheric nitrous oxide at each lake water temperature, and showed those as the line on each column in Fig. 3. The present results indicate that dissolved nitrous oxide concentrations in surface lake waters at all sites in this lake were supersaturated or at least equilibrated. The highest concentration in this lake was observed at Station-1 which is being strongly eutrophicated by input of polluted rivers, and was about 10 times higher than the solubility of atmospheric nitrous oxide.

Figure 4 shows seasonal variations in concentrations of dissolved nitrous oxide and nitrate 


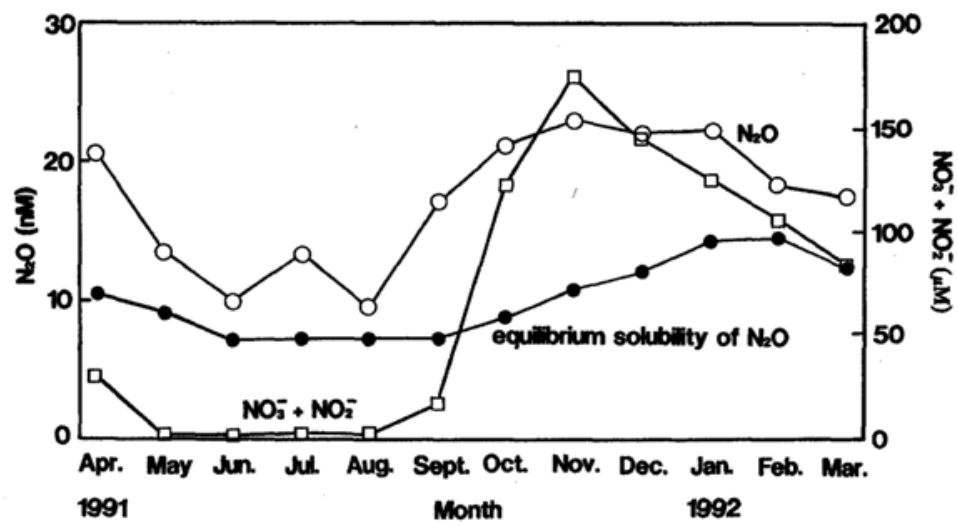

Fig. 4. Seasonal variations in dissolved nitrous oxide and nitrate + nitrite nitrogen concentrations in surface lake waters at Station-3, and saturation concentrations of atmospheric nitrous oxide at each water temperature.

plus nitrite-nitrogen in surface waters and saturation concentrations of nitrous oxide in each water temperature at Station 3. In Takahamairi Bay, the seasonal variation pattern that the concentrations of dissolved nitrous oxide were high in late-autumn to early spring and low in summer was very similar to that of nitrite plus nitrate-nitrogen, indicating that, during late spring to mid-summer, nitrite plus nitrate-nitrogen concentrations were extremely low and increased from early autumn to winter. These results can be interpreted as follows: little nitrification occurred in surface waters from late spring to midsummer because phytoplankton has consumed ammonium ion as a substrate for nitrification, but with decrease in phytoplankton activity from autumn to winter the rate of nitrification, that is, nitrate production, exceeded that of nitrate uptake by phytoplankton, and consequently the accumulation of nitrate occurred in the lake water (Takamura et al., 1987). This fact that the increase in nitrite plus nitrate-nitrogen concentrations was accompanied by the increase in nitrous oxide concentration suggests that the production of nitrous oxide in this lake was due to nitrification. No relationship between dissolved nitrous oxide and ammonium ion concentrations was found.

Water column in this lake was always aerobic throughout the year. Since denitrification is mediated by facultatively anaerobic bacteria, it

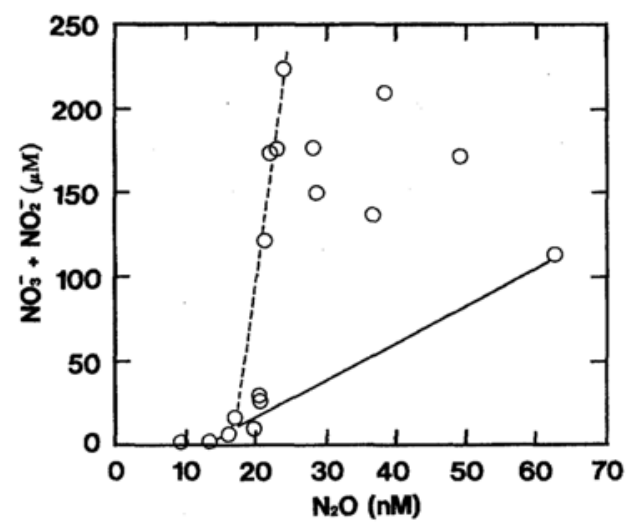

Fig. 5. Relationship between nitrous oxide and nitrate + nitrite-nitrogen concentrations at Stations-1 and 3. Dotted and solid lines indicate the postulated saturation concentration of nitrous oxide in lake water and the potential concentration of nitrous oxide produced during nitrification process in Takahamairi Bay, respectively.

seems likely that most of the dissolved nitrous oxide were produced at oxygen-depleted sediment surface (Koike et al., 1984; Hemond and Duran, 1989; Seitzinger, 1988).

Figure 5 shows relationship between nitrous oxide and nitrate plus nitrite-nitrogen concentrations in Takahamairi Bay, where the average depth is less than $\mathbf{3} \mathrm{m}$. If the increase in dissolved nitrous oxide concentrations was due to nitrification, and the nitrous oxide as an intermediate was produced at a constant portion during the nitrification process (Yoh et al., 1988), there 
would be a nearly linear relationship like the solid line in Fig. 5. However, a linear relationship was not observed in the present study. Thus, this result can reasonably be interpreted by assuming that because significant portions of the nitrous oxide produced have been shortly diffused into the atmosphere according to the extent of vertical mixing of lake water, the observed concentrations were scattered between the solid line and the dotted line, the latter of which corresponded to the postulated saturation solubility of atmospheric nitrous oxide in this lake because there was a nearly negative linear relationship between nitrite plus nitrate-nitrogen concentration and lake water temperature.

These results suggest that nitrous oxide as an intermediate may be being produced during nitrification process even in eutrophic shallow lakes without anaerobic hypolimnion, and that most of dissolved nitrous oxide in eutrophic shallow lakes may be shortly released to the atmosphere by vertical mixing of lake water after the production of nitrous oxide at oxygendepleted sediment surface.

In conclusion, the present study shows that dissolved nitrous oxide concentrations in surface lake waters at all sites in this lake were supersaturated or at least equilibrated, and that nitrous oxide may be being produced in many eutrophic shallow lakes, even though anaerobic layer is not formed in summer, and they can be one of the natural nitrous oxide emission sources.

Further study including that of direct release into the atmosphere by bubbling from sediment surface is needed to estimate annual emission amount of nitrous oxide from eutrophic shallow Lake Kasumigaura.

Acknowledgment-The authors thank Tsuneaki Maeda of DKK corporation for his help in this study.

\section{REFERENCES}

Benarde, M. A. (1992) Global warning, John Wiley \& Sons, p. 84-85.

Ebise, S. (1990) Water quality changes in a lake by pollutant load changes of inflow rivers. Kogai to Taisaku 26, 582-588 (in Japanese).

Goda, K., Muraoka, K., and T. Fukushima (1984) Phosphorus and nitrogen budget in Lake Kasumigaura. Res. Rep. Natl. Inst. Environ. Stud. Jpn. No. 54, 9-30 (in Japanese with English abstract).

Hemond, H. F. and Duran, A. P. (1989) Fluxes of $\mathrm{N}_{2}$ $\mathrm{O}$ at the sediment-water and water-atmosphere boundaries of a nitrogen-rich river. Water Resour. Res. 25 839-846.

Ibaraki University, Lake Kasumigaura Research Group. (1977), Lake Kasumigaura, Sankyo Publisher, p. 146-153.

Kawai, T., Otsuki, A. and Nishikawa, M. (1984) Concentrations of dissolved major ions in Lake Kasumigaura. Res. Data Natl. Inst. Environ. Stud. Jpn. No. 25, 151-171 (in Japanese).

Knowles, R., Lean, D. R. S. and Chan, Y. K (1981) Nitrous oxide concentrations in lakes: Variations with depth and time. Limnol. Oceanogr 26, 855866.

Koike, I., Nishio, T., and Hattori, A. (1984) Denitrification and nitrification in coastal and estuarine sediments. in Current Perspectives in Microbial Ecology, Klug, M. J. and Reddy, C. A. Eds., Amer. Soc. Microbiol.

Otsuki, A., Goma, R. F., Aizaki, M. and Nojiri, Y. (1993) Seasonal and spatial variations of dissolved nitrogenous nutrient concentrations in hypertrophic shallow lake, with special reference to dissolved organic nitrogen. Verh. Internal. Verein. Limnol. in press.

Rosswall, T. (1991) Greenhouse gases and global change. Environ. Sci. Technol. 25, 567-573.

Seitzinger, S. P. (1988) Denitrification in freshwater and coastal marine ecosystems: Ecological and geochemical significance. Limnol. Oceanogr. 33, 702-724.

Takamura, N., Iwakuma, T., \& Yasuno, M. (1987) Uptake of ${ }^{13} \mathrm{C}$ and ${ }^{15} \mathrm{~N}$ (ammonium, nitrate and urea) by Microcystis in Lake Kasumigaura. $J$. Plankton Res. 9, 151-165.

Terai, H., Yoh, M. and Saijo, Y. (1987) Denitrifying activity and population growth of denitrifying bacteria in Lake Fukami-ike. Jpn. J. limnol. 48, 211-218.

Thiemens, M. H. and Trogler, W. C. (1991) Nylon production: an unknown source of atmospheric nitrous oxide. Science 251, 932-934.

Weiss, R. F. and Price, B. A. (1980) Nitrous oxide solubility in water and seawater. Mar. Chem. 8, 347-359.

Weiss, R. F. (1981) The temporal and spatial distribution of tropospheric nitrous oxide. J. Geophys. 
Res. 86, 7185-7195.

Wetzel, R. G. (1975) Limnology, Saunders, p. 223253.

Yoh, M., Terai, H. and Saijo, Y. (1983) Accumulation of nitrous oxide in the oxygen deficient layer of freshwater lakes. Nature 301, 327-329.

Yoh, M., Terai, H. and Saijo, Y. (1988) A preliminary study on $\mathrm{N}_{2} \mathrm{O}$ production through nitrification in Lake Kizaki. Jpn. J. limnol. 49, 4346. 